INVESTIGACIÓN/RESEARCH

\title{
ALGUNOS APUNTES SOBRE LA FICCIÓN SERIADA NACIONAL: TIPOLOGÍA Y CARACTERÍSTICAS
}

María Marcos Ramos¹. Universidad de Salamanca. España mariamarcos@usal.es

\section{RESUMEN}

El artículo que se presenta analizará las tendencias en la ficción seriada nacional. Desde que la televisión se implantó en España uno de los objetivos era la de producir ficción nacional. Esta ha ido evolucionando con los años, llegando a profesionalizarse desde la entrada en el mercado de productoras como Globomedia. En los últimos años se ha vivido una eclosión de le ficción seriada nacional que ha conseguido desbancar de las parrillas televisivas a formatos tan asentados como la ficción extranjera, concursos y programas de telerealidad. La ficción se ha convertido, pues, en la marca de calidad de las cadenas que han protagonizado luchas encarnizadas para lograr esa audiencia fiel que tienen las series. Al éxito en España, se ha unido el éxito que la ficción seriada nacional logra en el extranjero, no solo logrando entrar en mercados muy asentados, como el francés o el inglés, sino cosechando numerosos premios en festivales especializados. Conocer las características de nuestra ficción televisiva es fundamental para poder comprender el éxito que ha alcanzado tanto en el mercado nacional como internacional.

PALABRAS CLAVE: Ficción nacional - serie - televisión - tipología.

\footnotetext{
${ }^{1}$ María Marcos Ramos: Doctoranda de Comunicación Audiovisual de la Universidad de Salamanca. España. Miembro del Observatorio de Contenidos Audiovisuales.

Correo: mariamarcos@usal.es
} 


\title{
SOME NOTES ON NATIONAL SERIALIZED FICTION: TYPES AND CHARACTERISTICS
}

\begin{abstract}
The present article will analyze trends in national serialized fiction. Since television was introduced in Spain one of the objectives was to produce national fiction. This has evolved over the years, to professionalize the entry into the market of producing as Globomedia. In recent years have witnessed an explosion of national serialized fiction he has managed to unseat of the schedule to formats as settled as foreign fiction, and reality television contests. The fiction has thus become the mark of quality from the chains that have staged feuds loyal audience to achieve that with the series. Success in Spain, has joined the success achieved national serialized fiction abroad, not only getting settled into niche markets, such as French or Spanish, but garnering numerous awards at specialized festivals. Knowing the characteristics of our television fiction is essential to understand the success it has achieved both national and international markets.
\end{abstract}

KEY WORDS: National fiction - series - television - typology.

\section{INTRODUCCIÓN}

En el presente artículo se estudiará el desarrollo diacrónico de la ficción audiovisual en la televisión española, así como su situación actual, incidiendo en las características de producción, las tipologías de series que se han realizado en España, el comportamiento de las audiencias, los métodos de trabajo más usados por guionistas y productores, la relación de las tramas ficcionales con la realidad, etc. Así, se intenta establecer un panorama lo más exhaustivo posible que permita comprender cuáles son las principales señas de identidad de las series de ficción televisiva española. Conocer las principales características de la ficción nacional permitirá comprender el éxito que estas producciones han alcanzado en la audiencia. Según el Anuario SGAE (VV.AA., 2011, p. 22), "el consumo de televisión en España ha ido incrementándose desde el año 2006, cerrando 2010 con un consumo medio de 234 minutos (persona/día), es decir, ocho minutos diarios más respecto a 2009". Consumo que ha aumentado también en el año 2011 hasta alcanzar los 239 minutos por persona y día, con cinco minutos más que en el año 2010, según se desprende del Análisis Televisivo 2011 (Barlovento Comunicación, 2011). Este informe añade que "en el conjunto de las seis cadenas nacionales más veteranas, el género que tiene una mayor presencia en las parrillas de programación es el entretenimiento, seguido de la ficción y la información" (Barlovento Comunicación, 2011, p. 9). Así, la ficción ocupa un $33 \%$ de la programación de las seis cadenas generalistas. Además, en dicho informe se señala que la ficción es el género predominante en Antena 3 (28.7\%), Cuatro (32.80\%) y la Sexta $(25.90 \%)$. Pero, ¿cómo es esta ficción? ¿Qué características tiene? ¿Cuáles son los principales rasgos de la ficción audiovisual nacional? Gracias a la lectura de este artículo se podrán conocer los rasgos definitorios de los programas que la audiencia 
ha elegido de manera mayoritaria para su entretenimiento televisivo.

\section{METODOLOGÍA}

Para realizar este artículo se ha seguido una metodología de carácter cualitativo basada en el estudio de casos como técnica de investigación. Gracias al análisis de diversas experiencias se podrán extraer conclusiones generales sobre la ficción televisiva que se está haciendo y sobre los cambios que se han dado en la industria televisiva. En esta investigación se ha realizado una revisión documental y gracias al análisis de las características más representativas, se ha extraído una serie de conclusiones.

El marco espacial de este artículo se centrará en el ámbito español con el fin de conocer y poder estudiar las diferencias iniciativas que se están llevando a cabo en nuestro país en la actualidad.

\section{ANÁLISIS Y DISCUSIÓN}

\subsection{Producción de ficción en España. Estado de la cuestión.}

En 1948 empezaron las emisiones televisivas en España, pero solamente en las ciudades de Madrid y Barcelona. La fecha oficial de inicio para las emisiones regulares de ámbito nacional fue 1956. Grosso modo, la televisión como primera y más importante opción de ocio para la mayor parte de la población hasta la década de 1970, cuando se consolidó su presencia en la gran mayoría de hogares españoles. En esa época, y hasta la llegada de las televisiones autonómicas y privadas en las décadas de 1980 y 1990, la única opción televisiva a la que podían optar los espectadores era la cadena pública, Radio Televisión Española (RTVE), con sus dos canales de emisión. El primer canal de la televisión pública empezó sus emisiones oficiales el 28 de octubre de 1956. Desde sus inicios, ha recibido varios nombres como VHF, Primer Programa, Programa Nacional, Primera Cadena, TVE1, La Primera, hasta que, con el nacimiento de las cadenas privadas, pasase a denominarse La 1, nombre con la que se le conoce en la actualidad. Por su parte, el segundo canal de TVE empezó sus emisiones en 1966. No será hasta 1990 cuando empiece a denominarse La 2. Antes recibió otros nombres como Segunda Cadena, Segundo Programa o TVE-2. Hasta la proliferación de los nuevos canales, el ente público vive su momento de máximo esplendor, consolidada en el mercado, con dos canales de emisión de diferente programación dirigidos a públicos alternativos y con un modelo de financiación basado, además de en las aportaciones públicas, en unos ingresos por publicidad controlados, por su carácter de único canal emisor, en régimen de monopolio.

Este panorama cambió a partir de la década de 1990. Tras la creación de los canales públicos autonómicos -a lo largo de los años ochenta se fueron creando una serie de televisiones autonómicas (que constituyeron la FORTA) en varias comunidades españolas gracias a la aprobación de la Ley del Tercer Canal de Televisión de 1983. EITB comenzó sus emisiones el 31 de diciembre de 1982, dos años más tarde, enero de 1984, sería el canal TV3 el que comenzase sus emisiones, a la que se uniría en julio de 1985 la Televisión de Galicia. TVGa y en 1987 Andalucía contaría con su canal 
autonómico, Canal Sur. En 1989 dos serían las comunidades que inaugurarían sus canales autonómicos: Comunidad de Madrid (Telemadrid) y Comunidad Valenciana (Canal 9). En la segunda mitad de los años noventa se han ido incorporando las televisiones autonómicas de las Islas Canarias (TVC) y de Castilla La Mancha (CMT), y antes los segundos canales de las emisoras de "primera generación" (ETB 2, Canal 33/K3, Punt 2, Canal 2 Andalucía, La Otra). En el año 2005 se crearon tres nuevas cadenas autonómicas en Islas Baleares, Aragón y Principado de Asturias, a las que se uniría, un año más tarde, la Radiotelevisión de la región de Murcia-, se produjo el nacimiento de las cadenas privadas: en un primer momento, Antena 3, Telecinco y el canal de pago Canal+-. A estas cadenas se unirían años más tarde Cuatro y La Sexta, ampliando aún más la oferta de canales y emisiones. En el año 1999 entró en funcionamiento la televisión digital terrestre (TDT) en España, otorgándose una licencia a cada una de las cadenas actuales, tanto públicas como privadas, además de otorgar tres múltiples y medio para canales nuevos. En el año 2005, se elaboró un Plan Técnico Nacional de la Televisión Digital Terrestre con la intención de impulsar esta tecnología. Entre las medidas que se establecían en este plan, habría que destacar el establecimiento del apagón digital en el 3 de abril de 2010 -momento a partir del cual todas las emisiones de televisión terrestres comenzaron a realizarse de manera digitaly el aumento en el número de emisoras de TDT. Este es el paradigma actual en el que se mueve la televisión española en la actualidad, a la que habría que sumar las cadenas locales: en definitiva, una treintena de canales a disposición de los televidentes.

\subsubsection{Auge de la ficción en España.}

Desde el nacimiento de la televisión, la ficción ha sido uno de los contenidos más importantes y que más atención ha tenido por parte de los responsables de contenidos de las cadenas y por los espectadores, siendo una de las opciones favoritas de consumo. Tal y como señala Torrado y Castelo, en última década (1995-2005),

las series de ficción de producción nacional han logrado en la última década un espacio prioritario en la parrilla televisiva. Sus emisiones han conseguido desplazar a los productos que ocupaban la franja horaria nocturna durante los primeros años de la televisión privada en España, aquellos comienzos de la "guerra de audiencias": los programas de entretenimiento, las películas de estreno o las series americanas (Torrado y Castelo, 2005).

Palacio (2008) distingue tres etapas en la televisión española. La primera, que abarcaría un periodo comprendido entre la fundación de la televisión hasta mediados de la década de 1960, se caracterizaría por la escasez: pocas horas de programación y, en consecuencia, pocos programas y poca variedad de formatos. La segunda, a la que denomina "televisión disponible", se desarrollaría hasta 1989 y estaría caracterizada por la creación de nuevos formatos y la progresiva variedad alcanzada por la parrilla de programación de los canales de RTVE. Por último, la tercera de las etapas, que iría hasta la actualidad -Palacio sitúa su final en 2005, por ser ese el último año del que se ocupa su estudio, pero podríamos extender su existencia hasta nuestros días sin problemas-, ha sido denominado como "abundancia televisiva", por la gran cantidad 
de oferta, en cuanto a canales, a parrillas de programación y a tipos de espacios televisivos, que pone a disposición del espectador y de los anunciantes. Aunque la categorización de Manuel Palacio se refiere al contenido televisivo en general y no a la ficción en particular, podemos utilizar su clasificación para repasar, de forma somera y sin ánimo de exhaustividad, la situación de la ficción $-\mathrm{y}$, de forma concreta, de la ficción de producción nacional- en la televisión española, que ha pasado de la práctica inexistencia a la saturación.

A lo largo del siglo XX y los primeros años del XXI, España ha pasado de no producir contenidos propios a situarse como el tercer país europeo en emisión de horas de ficción, tal y como señala el Informe de Eurofiction 1999 (Vilches et al., 1999). Según Vilches et al. (1999, pp. 10-11),

el caso de España es particularmente interesante porque ha pasado de una muy escasa producción propia en 1990 y 1991 (7 series en pantalla) a 36 títulos y 760 horas (con un aumento de más de 300 horas en los años 1997 y 1998) sin contar la producción de cadenas autonómicas. Si se tiene en cuenta que el aumento de horas se coloca preferentemente en la franja horaria de prime time y que las tres primeras series (comedias) del ranking superan los 10,7 y 5 millones de espectadores respectivamente, ya que estas producciones han vencido en audiencia no sólo al cine norteamericano sino también al fútbol, se puede obtener una idea aproximada de lo que bien se puede llamar el inicio de la etapa de industrialización de la ficción televisiva.

Son varios los factores que han propiciado esta proliferación de la ficción televisiva (Galán y Herrero, 2011). En la década de 1990, además de la aparición de las cadenas privadas de televisión, se crearon productoras independientes de televisión. Se incrementaron, por tanto, las horas de emisión a cubrir -y a rellenar- y los formatos a emitir, con una mayor fragmentación de la emisión y de la audiencia. A esto se unió la desregularización del mercado televisivo y la industrialización del proceso creativo, con una lógica mercantilista: se produce en aquello que se puede sacar beneficio. Era el comienzo en España de la industria televisiva tal y como se indica en el Informe Eurofiction (Vilches et al. 1999, p. 2) ya que "uno de los signos característicos de la industrialización del mercado televisivo fue su capacidad para producir teleseries diariamente, manifestando la necesidad de equipos de guionistas y de realización capaces de soportar el ritmo sostenido de una semana de trabajo, durante una temporada entera. Estos datos afectaron también al sistema de competencias: las series españolas ya no competían con las películas taquilleras norteamericanas, sino entre sí". Los programadores televisivos se dieron cuenta de que una de las preferencias de las audiencias eran los formatos de ficción, por lo que se convirtieron en uno de los motores de la programación, logrando los mejores shares de audiencia y un lugar privilegiado en el prime-time, desplazando a las series americanas, reinas de esa franja horaria hasta ese momento, y referente ineludible a la hora de crear producciones nacionales. De hecho, tal y como señala Pedro Sangro (2007, pp. 34-35), en España la producción de ficción televisiva se ha creado siguiendo las características de alguno de 
los siguientes formatos: sitcoms o comedias de situación o telecomedias; dramas, conocidas en España como series o teleseries; dramedias -son aquellas series que mezclan drama y comedia-; seriales, en las que se incluyen las soap operas anglosajonas y las telenovelas; $\mathrm{y}$, por último, los telefilmes o tv-movies.

En una mesa redonda constituida por especialistas e investigadores, cuyas conclusiones fueron recogidas en el libro Ficción televisiva: series (VV.AA., 1995, p. 125), se realizó un balance de la situación de la ficción nacional realizada en esos momentos. Uno de los ponentes, Joan Álvarez, señaló que

en España, las cadenas de televisión están viviendo sobre la ola del gusto por las series de ficción que se ha despertado en los últimos años; o que acaso las propias cadenas de televisión han sabido despertar en el público (...) Se trata de algo muy positivo. Primero porque supone la sustitución de lo que eran series de ficción de producción extranjera (sobre todo norteamericanas) por una producción propia, por la producción española; eso es realmente bueno para la industria audiovisual en su conjunto. En segundo lugar, porque está generando hábitos nuevos en el espectador, hábitos que tienen que ver con lo que puede ser una auto estimación de la vida cotidiana del espectador y también de las formas de cultura y estilos de vida que tienen esos espectadores.

Las cadenas de televisión siguen apostando hoy día por la producción de ficción y, de hecho, muchas de las cadenas han incorporado a sus plantillas la figura del "responsable de ficción", persona o equipo de personas que se encargan de elaboración de producción propia de la cadena. Esta apuesta por la serialidad en las cadenas de televisión constituye, en definitiva y más allá de las especifidades de la televisión nacional, "una de las expresiones más genuinas de la narrativa contemporánea" (Balló y Pérez, 2005 p. 9).

\subsubsection{Tipología de las series de ficción en España.}

Desde que se apostó por la ficción nacional, los programadores buscaron audiencias familiares y temas cercanos al público, de fácil consumo, que se desarrollaran en un entorno familiar para la audiencia, principalmente en un entorno familiar, profesional o de comunidad. La única premisa que debieron seguir los creadores y programadores era la búsqueda de "audiencias familiares que supusieran jugosos beneficios para los anunciantes y temas cercanos al público, principalmente comedias o relatos con dosis similares de drama y humor, que emanasen un fuerte sentimiento de comunidad y que transcurriesen principalmente en el barrio o en entorno familiar" (Galán y Herrero, 2011, pp. 27-28).

Las series de televisión realizadas en España han estado centradas en estas temáticas: series familiares -que giran en torno a una familia y/o comunidad-; series profesionales -aquellas que describen las rutinas y el día a día de un grupo de personas en torno a un centro de trabajo: bufete de abogados, comisaría de policía, 
hospital, periódico, etc.; o series históricas -aquellas que sitúan su marco de acción en el pasado o que recrean la vida de algún personaje histórico-.

\subsection{Series familiares}

Para Herrero y Diego (2009), las series familiares son propuestas en las que los sujetos destinatarios son los miembros de una familia y las historias suceden en el contexto doméstico y familiar. Medina (2008) establece una serie de requisitos que deben cumplirse para que una serie sea considerada como familiar. Uno de ellos es el contenido, de manera que la mayoría de las tramas se desarrollen en el ámbito doméstico - una casa o comunidad- y que los temas que trate sean los propios de la vida familiar, como la educación de los hijos, la relación entre los hermanos o la relación conyugal. El otro requisito está relacionado con los destinatarios de la serie. Se busca que se dirija a una audiencia amplia que abarque de niño a abuelos, buscando que la familia vea la serie junta. Se busca que exista una cierta afinidad y que se cree empatía entre los personajes de la ficción y los espectadores, por lo que las tramas que se desarrollan en la ficción acostumbran a estar lo más relacionados posible con la actualidad.

Dejando a un lado los precedentes históricos como La casa de los Martínez (1966-1970), la serie familiar de mayor importancia y repercusión en la ficción nacional contemporánea sería Farmacia de Guardia (Antena 3, 1991-1995). Estrenada en 1991 en Antena 3, a lo largo de sus seis temporadas, la serie contó las vicisitudes de una familia, los Segura, en un entorno profesional, una farmacia. Dirigida por Antonio Mercero, quien ya dirigiera otro de los clásicos de la televisión española, Verano Azul, la serie fue la primera producción de Antena 3. Tras cinco años en antena, el 28 de diciembre de 1995, Antena 3 emitió el último capítulo -con una duración superior a la habitual, 50 minutos frente a los 30 habituales- que alcanzó el $62.8 \%$ de cuota de pantalla con 11.527.000 espectadores de antena -llegando a un pico de audiencia de 13.850.000 de espectadores-.

Pero la que sin duda marcaría las pautas y premisas del formato en España sería Médico de familia (Telecinco, 1995-1999). Estrenada a finales de 1995 -ambas series competirían durante este año- la serie lideró la noche de los martes durante cuatro años, iniciando en España la tendencia de crear y consumir ficción nacional. Según García de Castro (2003, p. 5), la ficción televisiva de finales de los años noventa se caracterizó por: la hegemonía absoluta en el prime-time, sustituyendo a las series norteamericanas y desplazando de los horarios de máxima audiencia a otros géneros, como concursos, películas, etc.; la utilización de técnicas de realización más complejas, como la utilización de multicámara o trabajar con dos unidades de realización de manera simultánea para poder producir a un mayor ritmo. Además, el ritmo narrativo impuso que las tramas temáticas fueran madurando -con temáticas profesionales, con jóvenes, mayor acción e intriga-. Médico de familia representó una de los primeros intentos de estandarización del proceso de producción de series en España y supuso, además, la entrada la productora Globomedia en el mercado audiovisual nacional. La serie ayudó a consolidar un modo de producción y realización audiovisual importado de Estados Unidos- que fue aplicado no solo por las series de Globomedia, 
sino por muchas otras que se realizarían con posterioridad. Algunas de las novedades que impusieron fueron las siguientes: la elaboración de la "biblia" como guía a partir de la cual se desarrollan los diversos aspectos creativos y de producción de la serie; la duración de los capítulos en torno a sesenta minutos -hubo excepciones en la duración de los episodios ya que alguno de ellos llegarían a durar los noventa minutos-; la estandarización del guion en tres actos, separados por dos cortes de publicidad y con sus respectivos puntos de giro -cuando el capítulo duraba noventa minutos, el número de cortes publicitarios variaba, produciéndose tres o cuatro cortes por episodio-; el establecimiento de una lógica de trabajo en la que el proceso de creación de los guiones se realiza con un coordinador y un equipo de nueve guionistas, especializados en el medio televisivo, con amplios conocimientos sobre la estructura narrativa de las series americanas y que trabajan en grupos de tres, supervisados por un coordinador, que a su vez depende de un productor ejecutivo, que es el nexo de unión con la cadena; la aparición de los títulos de crédito y agradecimientos durante la conclusión del episodio y no a la finalización de este como se venía haciendo; la utilización de estudios previos que analizaban el comportamiento de la audiencia con algunos capítulos de la serie antes de su emisión. Se realizaron, además, estudios de audiencia, normalmente, en los primeros capítulos de cada temporada (Diego y Pardo, 2008, pp. 52-53). Tal y como explican Elena Galán y Begoña Herrero (2011, p. 38-39),

Globomedia, productora de la serie, contaba en esos momentos con una gran ayuda: los datos de audiencia de la empresa GECA. Tras un análisis exhaustivo (previo a la emisión del capítulo de la serie), se conocieron de antemano las preferencias de la audiencia, lo que permitió reorientar las tramas. Se hicieron reuniones de espectadores potenciales que, mediante un joystick, señalaban los momentos de la serie que les parecían más interesantes, lo que permitía eliminar fragmentos que no eran atractivos o reconvertir los guiones. Por otro lado, se remarcaron aquellos aspectos que mejor funcionaban, como el rodaje en exteriores y la temática de actualidad.

Al margen de los factores técnicos y productivos que se implantaron en Médico de familia, la serie también supuso la consolidación de las series familiares. Fueron muchas las que continuaron la estela iniciada por la serie realizada por Globomedia, aunque impusieron otros modelos de familia, tal y como señalan Galán y Herrero (2011, p. 31),

Médico de familia fue una serie voluntariamente arraigada en los resortes de la familia nuclear, estable y unida. El resto de las series familiares que fueron surgiendo con el paso del tiempo mostraron las transformaciones en curso que vivía la familia española (matrimonios separados, familias mono-parentales 0 las denominadas familias disfuncionales, parejas eventuales...).

Las series familiares que fueron surgiendo en el panorama audiovisual español supieron reflejar un mosaico de nuevas fórmulas de convivencia que pretendían establecer mejores y más eficaces relaciones comunicativas con el destinatario. Ya no 
se hablaba solo de la familia tradicional y nuclear, sino de todas aquellas fórmulas de convivencia familiares, reflejo de la sociedad en la que se enmarcan, como en la serie Javier ya no vive solo (Telecinco, 2001-2003) donde la familia estaba formada por un tío y unas sobrinas.

Las cadenas, especialmente las privadas, apostaron por la ficción produciendo numerosas series centradas en los problemas, las relaciones y el día a día de la familia española. Algunas de las series que podemos encuadrar en esta categoría son : Pepa y Pepe (TVE, 1995), Por fin solos (Antena 3, 1995), Menudo es mi padre (Antena 3, 19961997), 7 vidas (Telecinco, 1999-2006), ¡Ala Dina! (TVE, 2000-2002), Cuéntame (La 1, 2001Actualidad), Javier ya no vive solo (Telecinco, 2001-2003), Ana y los siete (La 1, 20022005), Los Serrano (Telecinco, 2003-2008), El pantano (Antena 3, 2003), Aqui no hay quien viva (Antena 3, 2003-2006), Casi perfectos (Antena 3, 2004-2005), Mis adorables vecinos (Antena 3, 2004-2006), Abuela de verano (TVE, 2005), Aída (Telecinco, 2005-Actualidad), La familia Mata (Antena 3, 2007-2009), La que se avecina (Telecinco, 2007-Actualidad), Los protegidos (Antena 3, 2010-2012), Los Quién (Antena 3, 2011), BuenAgente (La Sexta, 2011), entre otras muchas.

Todas estas series y algunas más de las que se han producido desde la irrupción de Farmacia de Guardia y, en especial, de Médico de familia -serie fundacional de esta categoría- representan familias que no pretenden ser verosímiles. Muchas de ellas buscan el humor a través de situaciones absurdas e inverosímiles, rozando el esperpento, como es el caso de Aquí no hay quien viva, Los Serrano o Aída, por citar alguna de ellas. Desde los despachos de los directivos se busca, además, con este tipo de series alcanzar a todo tipo de público, lo que hace que las familias protagonistas pertenezcan a una clase social media, con personajes cuyos baremos de edad va de los cero años hasta los cien, incluyendo a familiares de los protagonistas -tíos, abuelos, nietos, sobrinos, etc.- buscando una mayor identificación entre el público, como es el caso de Los protegidos, Ana y los siete o Cuéntame, entre otras. Utilizando estas estrategias se "consigue la identificación de mayor número de espectadores, asumiendo el peligro de crear una familia que se aleja de los estándares más extendido de la sociedad española" (Galán y Herrero, 2011, pp. 60-61).

\subsection{Series profesionales}

Manos a la obra (Antena 3, 1998-2001) y, en mayor medida, Periodistas (Telecinco, 19982002) fueron las que consolidado la categoría de series profesionales en el nuevo contexto que se vivió en la televisión española tras la irrupción de los canales privados, siguiendo una categoría que ya habían instaurado Turno de oficio (TVE, 19861987) o Brigada central (TVE, 1989-1990). Entendemos por series profesionales aquellas cuyo argumento gira en torno a una profesión y cuyos protagonistas la realizan. La mayor parte de las tramas se sitúan en el espacio de trabajo y las relaciones que se establecen entre los protagonistas son laborales, principalmente.

El comisario (Telecinco, 1999-2009), Raquel busca su sitio (TVE, 2000), Policías, en el corazón de la calle (Antena 3, 2000-2003), El grupo (Telecinco, 2000-2001), Hospital central (Telecinco, 2000-2012), Génesis: en la mente del asesino (Cuatro, 2006-2007), Cuenta atrás 
(Cuatro, 2007-2008), MIR (Telecinco, 2007-2009), Guante Blanco (La 1, 2008), Lex (Antena 3, 2008), UCO: Unidad Central Operativa (La 1, 2009), Los Misterios de Laura (La 1, 2009-Actualidad), Acusados (Telecinco, 2009-2010), La pecera de Eva (Telecinco, La Siete, Factoría de Ficción, 2010-2011), Cheers (Telecinco, 2011), Homicidios (Telecinco, 2011), Punta escarlata (Telecinco, 2011), etc. son algunos de los ejemplos de series profesionales que se han venido realizando en la televisión española.

A modo de resumen, la mayoría de estas series comparten características formales en su confección y realización: sus personajes pertenecen a una misma profesión - ahora, los principales estandartes, en su mayoría procedentes de campañas anteriores porque los productos crecen y se consolidan con el tiempo, reflejan la vida de los profesionales de la medicina (Hospital Central, Telecinco, 2000-2012), las fuerzas del orden (Policías, en el corazón de la ciudad, Antena 3, 2000-2003 y El comisario, Telecinco, 1999-2009), la enseñanza (Compañeros, Antena 3, 1998-2002), el derecho (Abogados, Telecinco, 2001), o el periodismo (Periodistas, Telecinco, 1998-2002) - y el protagonismo de la serie es coral -el peso de la acción recae sobre una pareja protagonista a los que acompañan una docena de secundarios, generalmente, de forma estable a lo largo de la temporada-. Las tramas que se desarrollan suelen ser duales en las que se alterna tanto la actividad profesional como la vida privada, pero cuando se desarrollan tramas personales suelen estar derivadas de conflictos profesionales, ya que la responsabilidad de los personajes es tan grande que en ocasiones su vida profesional llega a implicar a la personal: habitualmente, ninguno de los personajes, especialmente los protagonistas, es negligente o incumplidor y siempre su ética profesional está por encima, incluso, de intereses personales. En este tipo de series, además, la labor profesional se emplea como un trampolín para las relaciones afectivas, por lo que entremezclan tramas personales y profesionales. Estas series, a diferencia de las familiares, suelen basar sus tramas en acontecimientos de actualidad, muchos de ellas extraídas de noticias en boga, o en valores sociales vigentes, con escenarios creíbles.

Medina (2008, p. 64) señala alguno de los aspectos que han podido influir para que estas series -de orientación más realista- hayan sido ampliamente aceptadas por el público: "estilos de vida que ofrecían, el reflejo de la sociedad del momento y, en definitiva, aquello que la audiencia demandaba y le gustaba ver. Sin embargo, en algunas ocasiones, el telespectador no se veía (...) y su vida diaria transcurría por derroteros muy diferentes". De hecho, algunas de estas series profesionales han llegado a influir tanto en los telespectadores que han sido numerosas las carreras universitarias que han sufrido un incremento en sus matriculaciones debido al éxito de una serie de televisión. Por ejemplo, la Facultad de Medicina de la Universidad de Zaragoza ha realizado un estudio en el que se analiza los motivos que han llevado a los alumnos a matricularse en medicina y un 11\% del alumnado admite que ha seleccionado carreras como Periodismo, Psicología o Derecho influidos por las series de televisión. La serie española Periodistas (Telecinco, 1998-2002) fue la desencadenante de que muchas facultades de Ciencias de la Información estuvieran llenas de alumnos durante los años en que se emitió la serie, de 1998 a 2002.

Se han dado, además, otras series que mezclaban a partes iguales tramas familiares y profesionales. Algunas de las series que podríamos enmarcar en este tipo son: Querido 
maestro (Telecinco, 1997-1998), Compañeros (Antena 3, 1998-2002), Los hombres de Paco (Antena 3, 2005-2010), Hermanos y detectives (Telecinco, 2007-2009), Herederos (La 1, 2007-2009), Física o Química (Antena 3, 2008-2011), Estados alterados Maitena (La Sexta, 2008-2010), Doctor Mateo (Antena 3, 2009-2011), Pelotas (La 1, 2009-2010), Gavilanes (Antena 3, 2010-2011), etc.

\subsection{Series históricas}

Otra de las tendencias que más se han ido asentando en la parrilla televisiva española es la de las series históricas -hay que señalar que la edad de oro de la ficción histórica en España no está siendo un hecho aislado de nuestro país, ya que esta fiebre por la recreación histórica a través de la ficción se está dando por ejemplo en Portugal, Francia e Italia. Se ha producido, por tanto, una internacionalización de formatos televisivos que, por otra parte, están funcionando muy bien-, estrechamente vinculados con el subgénero narrativo histórico, de gran relevancia en el cine y en la literatura. Entendemos por series históricas aquellas que recrean hechos históricos o bien sitúan sus tramas de acción en el pasado, generalmente indeterminado, como Águila Roja (La 1, 2009-Actuliadad) -la serie está ambientada en la España del siglo XVII, pero sin especificar ni el lugar ni el tiempo concreto de acción-. Muchas de estas series se han realizado en formato de tv-movie con, generalmente, dos entregas. Algunas de las tv-movies que se han realizado en los últimos años recreando hechos históricos son: 23-F. Historia de una traición (Antena 3, 2009), La princesa de Éboli (Antena 3, 2011), Clara Campoamor, la mujer olvidada (La 1, 2011), Tres días de abril (La 1, 2011), El asesinato de Carrero Blanco (La 1, 2011), Isabel, mi reina (La 1, 2012), etc. Amar en tiempos revueltos (La 1, 2005-2012), una de las más longevas en esta categoría, comenzó a emitirse en el 2005 en las sobremesas de la cadena pública. La serie cuenta, de lunes a viernes, las vivencias de unos personajes tras la guerra civil en los primeros años del franquismo. La cadena pública supo aprovechar el tirón comercial de esta serie y realizaría La Señora (La 1, 2008-2010) y un spin-off de ésta, 14 de abril. La república (La 1, 2011). En Antena 3 este tipo de serie está representada por Hispania (Antena 3, 2010Actualidad), El secreto de Puente Viejo (Antena 3, 2011-Actualidad), Bandolera (Antena 3, 2011-Actualidad), Toledo: cruce de destinos (Antena 3, 2012), entre otras. Vientos de Agua (Telecinco, 2006), Tierra de Lobos (Telecinco, 2010-Actualidad) y Piratas (Telecinco, 2011) son alguna de las apuestas de Telecinco por este género.

\subsection{Forma de trabajo en las series de ficción nacional: autoría vs. Factoría.}

En España conviven en estos momentos dos modos o procedimientos para escribir guiones para series de televisión. Por un lado, podemos hablar del método tradicional o de autoría, que consiste en que un solo guionista realiza, una vez definida la trama, el guion entero del capítulo. Ignacio del Moral (2009, p. 50), uno de los defensores -y representantes- de este método, que ha utilizado en series como Cuéntame, lo describe de la siguiente manera:

Como procedo del teatro, el método que he seguido es más artesanal. 
Al empezar con [Antonio] Mercero, siempre he intentado seguir su método. Consiste en juntarse los guionistas y ver los argumentos de la serie y luego cada guionista se centra en su guion. Existe la figura del responsable [Coordinador de guiones] que se encarga de controlar los guiones y los llega a retocar. Siempre he intentado salvaguardar la autoría, aunque a veces es complicado porque las cadenas y las productoras quieren tener un poco más de control. Ahora en Cuéntame me he encontrado con antiguos compañeros que también defienden este método [como Eduardo Ladrón de Guevara o Carlos Molinero, por ejemplo], que tiene la ventaja de que es mejor para el autor y la desventaja de que los guiones no son tan estándares y eso no les suele gustar a las cadenas y a las productoras porque no sales guiones tan pautados como normalmente.

Frente a este método, estaría el denominado de "factoría", implantado en España por la productora Globomedia a mediados de la década de 1990. En este método de trabajo prima la concepción "industrial" -y no "artesanal" - del guion, así como el trabajo en equipo. Tal y como señala Miguel Ángel Huerta (2007, p. 23),

los responsables de Cuéntame cómo pasó o El Comisario prefirieron apostar por el mantenimiento de ciertos rasgos de autoría. La escritura individualizada de capítulos, a pesar de que parece estar en vías de extinción, sigue ejercitándose gracias a las convicciones de narradores tan consagrados como Eduardo Ladrón de Guevara e Ignacio del Moral. Es más, el primero de ellos, defiende el carácter artesanal de su trabajo y se define a sí mismo como "uno de los últimos mohicanos del guion televisivo". El veterano escritor reconoce, además, que "aunque el modelo de trabajo en equipo también puede llevar al éxito, nosotros trabajamos más a gusto con un guionista que desarrolle todas las tramas de un capítulo". Así, en los dos títulos mencionados existen unos coordinadores que se responsabilizan de la parcela narrativa, pero la elaboración concreta de cada guion es, en principio, responsabilidad de un solo profesional al que se le encarga la tarea.

Huerta (2007, p. 22) describe el método de trabajo empleado por Globomedia, en el que habitualmente se cuenta con cuatro equipos formado por cuatro guionistas que se reparten los capítulos y los trabajan de forma autónoma. Las directrices que deben seguir están establecidas en la biblia y en los denominados "mapas de tramas" y, de forma más esquemática, en la escaleta que se elabora para cada capítulo, en la que se fija el "pulso dramático" por escena. Cada escaleta, una vez aprobada, es dividida en escenas que cada guionista debe desarrollar y dialogar por separado. Una vez realizado el trabajo, ha de ser aprobado por el jefe de equipo. Finalmente, el guion definitivo se presenta a los actores quienes, en la "mesa italiana", leen en voz alta el texto y se introducen algunas matizaciones. De esta puesta en común saldrá el guion definitivo. Como se puede observar, a diferencia del modelo anterior, la autoría del guion no se puede identificarse con ningún autor en concreto, sino que el proceso de 
creación es totalmente colectivo.

Otra estrategia impuesta por Globomedia para que sus diálogos sean más reales es la utilización de la llamada "writer's room", una sala de reunión en la que se hace una lectura del guion para que los profesionales más hábiles en la creación de gags verbales y visuales -en el ámbito anglosajón se denominan "one liners", que se podría traducir como escritores de línea- enriquezcan el nivel humorístico de cada entrega.

Sobre las ventajas de este método, los profesionales consultados citan la estimulación de una cierta estabilidad laboral -ya que se trabaja para la productora y no para la serie-, así como la profesionalización de la labor del guionista debido a la creación de una industria audiovisual. Entre las desventajas, se destacan el encorsetamiento de las producciones, la pérdida de frescura y una cierta automatización en una labor de corte artístico -y que, por tanto, debería ser libre-.

\section{4. ¿De dónde vienen las ideas? Realidad vs ficción.}

Son muchas las series nacionales que venden sus historias como reales o como recreaciones de la sociedad actual, pero, ¿es esto verdad? ¿Son las series españolas fiel reflejo de la realidad o se basan en esta para desarrollar sus tramas y para adaptarlas a lo que Jean-Claude Carriére y Pascal Bonitzer (1991, p. 36) señalan como la única condición que una historia debe tener, que no es otra que la de "cautivar y mantener la atención del espectador"?

Si se analiza el contexto temporal en el que se basan la mayoría de las series españolas con mayor índice de audiencia, éstas se enmarcan en la actualidad y en un reflejo lo más cercano posible al contexto social en el que se emiten. García de Castro (2008) utilizó el término nuevo realismo o "neorrealismo" televisivo contemporáneo para hacer referencia al sustrato narrativo que presentaban estas nuevas series, cuyas características predominantes era el realismo y la contemporaneidad. Las tramas de las series, desde Farmacia de guardia (Antena 3, 1991-1995) o Médico de familia (Telecinco, 1995-1999), hasta las más actuales, como Homicidios (Telecinco, 2011) o Con el culo al aire (Antena 3, 2012-Actualidad), se sucedían en el "aquí" y "ahora" de los momentos de producción -aunque en las series no se solía hacer referencias explícitas ni del tiempo ni del lugar de acción- que se manifiestan con los elementos de referencialidad de las historias, y los resortes de conexión y de pertenencia a la comunidad. De hecho, muchas de las series se fueron adaptando a los nuevos valores morales o sociales de la modernidad, como se puede ver en la incorporación en las series Aquí no hay quien viva (Antena 3, 2003-2006) u Hospital Central (Telecinco, 20002012) de parejas estables de homosexuales coincidiendo con la aprobación del matrimonio entre personas del mismo sexo. No obstante, todas estas innovaciones siempre se producen desde un prisma conservador que casi nunca trasciende lo que en cada época se considera "políticamente correcto", puesto que, en el fondo, lo que buscan las series es abarcar el número máximo de espectadores de diferente clase social, económica, condición... y no herir sensibilidad o producir rechazo de parte del público potencial. Sobre este respecto, las profesoras Elena Galán y Begoña Herrero afirman que (2011, p. 99) 
en la actualidad, el hiperrealismo que caracteriza a la televisión encuentra en las historias de la ficción - amores, odios, pasiones, venganzas, crímenes- el terreno propicio para reflejar, reflexionar, reiterar o experimentar las diferentes posibilidades de relación entre las estructuras dominantes de la sociedad ("nosotros") y las marginales ("los otros").

Pero, que las series se basen en el aquí y ahora, ¿significa que deben tener en cuenta la realidad? ¿O qué deban reflejarla tal cuál es? ¿No sería, pues, un documental y no una serie de ficción? ¿Se puede o se debe reflejar la realidad en la ficción? ¿O solo se debe entretener al espectador? Quizás sean estas algunas de las cuestiones que se plantean los guionistas, productores y realizadores a la hora de afrontar un nuevo producto televisivo en formato de ficción. Alba (1999, p. 187) señala que "la ficción no examina la realidad sino la existencia. Y la existencia no es lo que ya ha ocurrido, la existencia es (...) todo lo que el hombre puede llegar a ser (...). Existir quiere decir: 'ser-en-elmundo'. Hay que comprender como posibilidades tanto al personaje como su mundo".

Las noticias y la realidad proporcionan a los guionistas ideas de conflictos, dramas, personas e historias que, llevadas y adaptadas para el lenguaje audiovisual, convierten a estas personas en personajes y a estas pequeñas historias en relatos ya que "un periódico diario puede aportarle al guionista atento, que lo lee buscando posibilidades dramáticas, una infinidad de historias ya finalizadas" (Alba, 1999, p. 187). Sin embargo, son varios los guionistas que, aunque señalan que la realidad es una fuente de ideas, se muestran contrarios a plasmarla de manera fidedigna. La guionista Alicia Luna reflexionaba, en el IV Encuentro de Desarrollo de guiones organizado por Alma y la Conserjería de Cultura y Turismo de la Comunidad Autónoma de Madrid celebrado en noviembre 2008, acerca de la creatividad. Para ella, para poder ser creativo hay que alejarse a la realidad ya que "los creadores debemos observar, pero si plasmamos únicamente estamos haciendo documentales, no ficción. Hay que alejarse de la realidad porque muchas veces se puede saltar la realidad sin herirla". En parecidos términos se ha expresado Ignacio del Moral, para quien "no se debe escribir sobre nada. Cada momento pide una cosa o varias cosas al tiempo. En cada momento $\mathrm{y}$ en todos los géneros conviven ficciones que buscan ser provocadoras y ficciones que pretenden ser más lenitivas. Responden a distintas necesidades sociales (del Moral, 2009, p. 70)". En el fondo, lo que plantean reflexiones como estas es la necesidad de que las series televisivas $-y$ todos los relatos en general- hablen de la realidad a la que se dirigen $\mathrm{y}$, al mismo tiempo, de todas las realidades posibles.

\section{CONCLUSIONES}

España es uno de los países que mayor ficción nacional crea y consume. En los últimos años, la ficción nacional ha crecido no solo cuantitativamente -la emisión anual de ficción ronda las 1.500 horas- sino cualitativamente. A partir de los años 90, ha habido un cambio de ciclo en las productoras y cadenas, por el que se ha comenzado a realizar una nueva ficción y se han desarrolla estrategias empresariales enfocadas a la 
conquista de audiencia y de nuevos mercados, tal y como demuestra el éxito de las series españolas en mercados tan competitivos como el italiano, el francés o el inglés. Estas series de televisión venden, además, una imagen de marca España en el extranjero.

El aumento de las series nuevas, la continuación de la mayoría de ellas e incluso que se haya realizado un spin-off son muestras inequívocas del éxito de la ficción nacional y del asentamiento de esta opción de entretenimiento entre el público español. Bien es cierto que la ficción nacional presenta varias carencias, como una excesiva duración de los capítulos -los sesenta minutos de media por capítulo es excesiva para poder explorar nuevas formas de narración, además de ser una duración poco utilizada en la ficción internacional, donde los capítulos suelen durar o veinte minutos o cuarenta-, la tendencia costumbrista de sus tramas -ya se desarrolle la acción en un barco, en un colegio o en un bar al final todas las series están cortadas por el mismo patrón narrativo-, y, la poca fragmentación de audiencias -todos los contenidos deben buscar el mismo público, a ser posible, aquel que agrupe desde niños a abuelos de todos los tipos posibles de familia-. Que no se puedan hacer series más específicas sin que tengan que aglutinar grandes audiencias está derivado de la excesiva duración, pero, especialmente del costumbrismo, tan asentado en nuestra ficción. Quizá, con el auge de la ficción extranjera, especialmente la que se está haciendo en las cadenas de cable norteamericana, nuestra ficción empieza a quitarse las etiquetas del costumbrismo y busque una mayor fragmentación de audiencias, donde no todas las series sean de familias, compañeros de trabajo o históricas.

\section{REFERENCIAS}

ALBA, G. (1999). Cómo construir personajes a partir de la prensa diaria. En Vilches, L. (Comp.), Taller de escritura para televisión. Barcelona: Editorial Gedisa.

BALLÓ, J., y PÉREZ, X. (2005). Yo ya he estado aquí. Ficciones de la repetición. Barcelona: Anagrama.

CALABRESE, O. (1989). La era neobarroca. Madrid: Cátedra.

CARRIÈRE, J. C. y BONITZER, P. (1991). Práctica del guión cinematográfico. Barcelona: Paidós Comunicación.

DEL MORAL, I. (2009). Guiones para TV. Madrid: Editorial Fragua.

DIEGO, P. y PARDO, A. (2008). Estándares de producción de "dramedias" familares en España. En: MEDINA, Mercedes (Coord.). Series de television. El caso de Médico de familia, Cuéntame cómo pasó y Los Serrano. Madrid: Yumelia.

ECO, U. (1988). La innovación en el serial. En ECO, U., De los espejos y otros ensayos. Barcelona: Lumen.

GALÁN, E. y HERRERO, B. (2011). El guion de ficción en televisión. Madrid: Editorial 
Síntesis.

HERRERO SUBÍAS, M. y DIEGO GONZÁLEZ, P. (2009). Series familiares de televisión: concepto, producción y exportación. El caso de Médico de familia, en Revista Latina de Comunicación Social, 64. Disponible en http://www.revistalatinacs.org/09/art/21_820_19_UNAV/Herrero_y_Diego.html [Fecha de consulta: 07 de Septiembre de 2012].

HUERTA, M. Á. (2007). Las series de televisión en España: antecedentes históricos, condicionantes básicos y métodos de trabajo, en HUERTA, M. A. y SANGRO, P. , De los Serrano a Cuéntame. Cómo se crean las series de televisión en España. Madrid: Arkadin Editores

HUERTA, M. Á. y SANGRO, P. (2007). De los Serrano a Cuéntame. Cómo se crean las series de televisión en España. Madrid: Arkadin Editores.

MEDINA, M. (coord.) (2008). Series de televisión. El caso de "Médico de familia", "Cuéntame cómo pasó" y "Los Serrano". Madrid: Ediciones Internacionales Universitarias.

PALACIO, M. (2008). Historia de la televisión en España. Madrid: Gedisa.

SALÓ, G. (2003). ¿Qué es eso del formato? Como nace y se desarrolla un programa de televisión. Barcelona: Gedisa.

TORRADO, S. y CASTELO, C. (2005). Series de ficción de producción nacional y telespectadores: un negocio en bandeja, en Comunicar, $\mathrm{n}^{\circ} 25$.

VILCHES, L. , BERCIANO, R., LACALLE, C.., ALGAR, S. y POLO, S. (2000). Informe Eurofiction 1999: Menos familia y más policía, en Zer: Revista de estudios de comunicación $=$ Komunikazio ikasketen aldizkaria, $n^{\circ} 9$.

VV.AA. (1995). Ficción televisiva: series. Madrid: SGAE.

VV.AA. (2011). Anuario SGAE de las Artes Escénicas, Musicales y Audiovisuales 2011. Madrid: SGAE.

VV.AA. (2011). Análisis Televisivo 2011. Madrid: Barlovento Comunicación.

\section{María Marcos Ramos}

Licenciada en Comunicación Audiovisual por la Universidad del País Vasco y doctoranda de Comunicación Audiovisual en la Universidad de Salamanca, donde se encuentra realizando su tesis doctoral. Ha realizado trabajos de investigación sobre lenguaje cinematográfico, alfabetización mediática y TIC's en revistas y monografías científicas. Sus líneas de investigación actuales son la alfabetización mediática, la ficción cinematográfica y la imagen de los inmigrantes en la ficción nacional emitida 
en prime time, tema sobre el que realiza su tesis doctoral. 